Acta Sci. Pol. Technol. Aliment. 15(3) 2016, 233-245

pISSN 1644-0730

eISSN 1889-9594

DOI: $10.17306 /$ J.AFS.2016.3.23

ORIGINAL PAPER

Received: 18.10 .2015

Accepted: 18.03.2016

\title{
EFFECT OF FOOD PROCESSING ON THE PHYSICOCHEMICAL PROPERTIES OF DIETARY FIBRE
}

\author{
Vasfiye Hazal Ozyurt ${ }^{1}$, Semih Ötles ${ }^{2 \bowtie}$ \\ ${ }^{1}$ Graduate School of Natural and Applied Sciences, Food Engineering Branch, Ege University \\ 35100 Izmir, Turkey \\ ${ }^{2}$ Food Engineering Department, Faculty of Engineering, Ege University \\ 35100, Izmir, Turkey
}

\begin{abstract}
Products derived from the manufacturing or processing of plant based foods: cereals, fruits, vegetables, as well as algae, are sources of abundant dietary fibre. Diets high in dietary fibre have been associated with the reduced risk of cardiovascular disease, diabetes, hypertension, obesity, and gastrointestinal disorders. These fibre-rich products and byproducts can also fortify foods, increase their dietary fibre content and result in healthy products, low in calories, cholesterol and fat. Traditionally, consumers have chosen foods such as whole grains, fruits and vegetables as sources of dietary fibre. Recently, food manufacturers have responded to consumer demand for foods with a higher fibre content by developing products in which highfibre ingredients are used. Different food processing methods also increase the dietary fiber content of food. Moreover, its chemical and physical properties may be affected by food processing. Some of them might even improve the functionality of fibre. Therefore, they may also be applied as functional ingredients to improve physical properties like the physical and structural properties of hydration, oil-holding capacity, viscosity. This study was conducted to examine the effect of different food processing methods on the physicochemical properties of dietary fibre.
\end{abstract}

Key words: dietary fiber, insoluble dietary fiber, soluble dietary fiber, physicochemical, processing

\section{INTRODUCTION}

Dietary fibre is the edible parts of plants, or similar carbohydrates, which are resistant to digestion and absorption in the small intestine (Almeida et al., 2013). Natural sources of dietary fiber are found in the complex mixture of polysaccharides, which make up the cell walls of fruit, vegetables, and whole-grain cereals (Redgwell and Fischer, 2005). However, knowledge on dietary fibre has improved significantly in both physiological and analytical areas over the last decades. Dietary fibre has a lot of positive health effects, such as bowel function, reduced risk of coronary heart disease, type 2 diabetes and improved weight maintenance.
Many analytical methods and definitions have evolved over the years. Therefore, approximately comparable dietary fibre values were produced and presented in food composition databases for use in food research, the food industry and for nutritional counselling and education. Nowadays, dietary fibre is one of the components in foods that cause a lot of confusion among users and producers of food composition data (Westenbrink et al., 2013). The physiological effect of dietary fibre depends first of all on its origin, the proportions of individual fractions, the degree of comminution of raw materials and the thermal processes applied. 
The insoluble fraction of dietary fibre that activates intestinal peristalsis is capable of binding bile acids and water. Soluble fibre reduces the blood cholesterol level, the risk of ischemic heart disease and postprandial glycemia. The functional properties of dietary fibre, such as its water-holding capacity, cation binding and sorption of bile acids, play a significant role in the prevention of diet-dependent diseases, e.g. obesity, atherosclerosis and colon cancer (Dziedzic et al., 2012).

Many studies have highlighted that the consumption of foods rich in dietary fibre may improve health: the recommended intake is $30-45 \mathrm{~g}$ per person per day, yet the current consumption of fibre in the West is only around $20 \mathrm{~g}$ /day person. Because processing operations and their arrangement during complete processing may play a role in fibre content and in the type of fibre remaining in the final product, the processing of the sample is important (Colin-Henrion et al., 2009). This review summarises recent research regarding the effect of food processing on the physochemical properties of dietary fiber.

\section{WHAT IS A DIETARY FIBRE?}

Relevance for dietary fibre has been advanced in recent decades. Although knowledge on dietary fibre has developed in recent decades, there is still no generally accepted definition of dietary fibre (Mudgil and Barak, 2013). In 1953 Hipsley was first to determine the term 'dietary fibre' for the non-digestible constituents of plant cell walls. Many international definitions are used for dietary fibre (Philips, 2013). The whole dietary fibre definitions refer to non-digestible constituents of plant cell wall (Slavin, 2005). New definitions for dietary fibre was existed and expanded. The latest definition proposed by the Codex Committee on Nutrition and Foods for Special Dietary Uses (2009) is as follows: "Dietary fiber is the edible carbohydrate polimers of plants, obtained carbohydrate polymers from food raw material by physiological or chemical treatments and has been shown to have a physiological effect or benefit to health". Dietary fibre generally has such properties as decreased intestinal transit time and increased stool bulk; it is fermentable by colonic microflora; it reduce blood total and/or LDL cholesterol levels; and reduces post-prandial blood glucose and/or insulin levels (Philips, 2013).
The chemical nature of "dietary fibre" comprises a heterogeneous collection of chemically different plant components (Hollmann et al., 2013). Dietary fibre includes non-digestible polysaccharides (cellulose, $\beta$-glucan, hemicelluloses, pectin, inulin, resistant starch) (Buttriss and Stokes, 2008; Mildner-Szkudlarz et al., 2013; Mudgil and Barak, 2013; Prosky, 2000), non-digestible oligosaccharides (fructo-oligosaccharides, oligofructose, galacto-oligosaccharides, soybean oligosaccharides, raffinose and stachyose) (Elleuch et al., 2011), synthesized carbohydrate polymers (polydextrose) (Mudgil and Barak, 2013), resistant maltodextrin (Buttriss and Stokes, 2008; Hollmann et al., 2013; Westenbrink et al., 2013), lignin (Elleuch et al., 2011), hydrocolloids (gelatin, starch, gums, mucilage, xanthan gum, and cellulose derivatives) (Buttriss and Stokes, 2008) and other associated substances of plant origin (waxes, phytate, cutin, saponins, suberin, tannins) (Mudgil and Barak, 2013). The molecular structure of chitosan, which is an example of fibre of animal origin, is similar to that of plant cellulose (Elleuch et al., 2011). The chemical composition of dietary fibre is characterised by its sugar residues and by the nature of the bond between them.

\section{Cellulose}

Cellulose is the structural polysaccharide present in plant cell walls (Molist et al., 2014) and is an unbranched polymer chain consisting of up to 10,000 glucose monomer units per molecule (Mudgil and Barak, 2013) linked by b-(1-4) glycosidic bond (Olson et al., 1987). Because it is insoluble in water, it increases fecal volume as well as promoting regular bowel movements, eliminating possible carcinogens and shortening bowel transit time. Cellulose digested by beneficial microflora in the gut and degraded by natural fermentation in colon produces a significant amount of short-chain fatty acids, which feed our intestinal cells (Mudgil and Barak, 2013).

\section{$\beta$-glucan}

$\beta$-glucan is a linear polysaccharide of glucose monomers with $\beta(1 \rightarrow 4)$ and $\beta(1 \rightarrow 3)$ linkages (Johansson et al., 2000). Unlike those in cellulose, the linkages between the units are variable (Mudgil and Barak, 2013). 


\section{Hemicellulose}

Hemicellulose is second to cellulose in abundance ( $\mathrm{Lu}$ and Mosier, 2008), but differs from cellulose in having monomer units other than glucose (Mudgil and Barak, 2013). It contains different sugar monomers, like mannose, arabinose and xylose. It is a branched polymer and consists of shorter chains than cellulose (500-3000 sugar units) (Celebioglu et al., 2012). Chemically, hemicelluloses can be grouped into four classes: xylans, xyloglucans, mannans and mixed linkage $\beta$-glucans. Xylans are composed of a backbone of $\beta$ - $(1 \rightarrow 4)$-D-xylose units with side chains containing different sugars and sugar acid residues. These side chains comprise arabinose, glucose, galactose and in lower amounts, rhamnose, glucuronic acid and galacturonic acid. Xyloglucan is similar to the backbone of cellulose, consisting of $\beta$-( $1 \rightarrow 4)$-linked D-glucopyranose units, but with frequent branching of $\alpha$-D-xylose residues. Glucomannans consist of a branched backbone of $\beta$ - $(1 \rightarrow 4)$-linked D-mannose and D-glucose units. A fourth type of hemicelluloses are mixed $(1 \rightarrow 3,1 \rightarrow 4)$ linked $\beta$-glucans, which are restricted to grass species and some pteridophytes (Schadel et al., 2010). Structually, hemicellulose is heterogenous with its structure and composition changing from plant sources and geographical origins of the plants (Juturu and $\mathrm{Wu}, 2012$ ).

Hemicelluloses promote regular bowel movements by increasing hydration of the stool. Furthermore, hemicelluloses directly bind cholesterol in the gut by preventing cholesterol absorption. They are digested by bacteria in the gut because hemicelluloses increase the number of beneficial bacteria in the gut and create short-chain fatty acids. These fatty acids are used by colon cells as fuel, hence cholesterol is decreased (Mudgil and Barak, 2013).

\section{Pectin}

Pectin represents a very complex family of plant cellwall polysaccharides (Sila et al., 2009), consisting of $\alpha-(1,4)$-linked homogalacturonan and rhamnogalacturonan highly branched with various neutral sugar glycans (Yoo et al., 2012).

\section{Inulin, fructo-oligosaccharides and oligofructose}

Fructo-oligosaccharides can also be synthesized from monosaccharides and disaccharides by chemical or enzymatic processes and from polysaccharides by enzymatic hydrolysis (Ferguson et al., 2001), comprising of 1-kestose, nystose and 1f-B-fructo-furanosylnystose B-D-((2,1)-fructofuranosyl) (Tungland and Meyer, 2002). Short-chain fructo-oligosaccharides are known as oligofructose $(n=1-8)$, while medium-chain fructo-oligosaccharides are known as inulin $(n=10-13$ on average and 63 at maximum) (Morris and Morris, 2012). Inulin and short-chain FOS vary in degrees of polymerization ranging from 2 to 60 (inulin) or 2 to 20 (oligofructose) (Chawla and Patil, 2010). Inulin is a polymer of fructose monomers (Lattimer and Haub, 2010), and is a mixture of oligomer and polymer chains with a variable number of fructose molecules, joined by B bonds (2-1) (linked by $\beta$-(2-1)-D-fructosyl-fructose bonds) (Foschia et al., 2013; Leroy et al., 2010). It also usually includes a glucose molecule at the beginning (Franck and Levecke, 2012) or end of the chain (Villegas et al., 2007).

\section{Resistant starch}

If starch or its hydrolysis products is not digested in the gut, they pass into the large intestine, where they may be fermented. This is known as resistant starch (RS). All starch can be degraded by human a-amylase. However, the rate and extent to which it is digested in the small intestine determines its physiological properties. Resistant starches are divided into four subfractions: (a) physically starch, as RS1, (b) natural starch granule, as RS2, (c) retrograded starch, RS3 (Cummings et al., 2004), (d) chemically modified starch (RS4). These are also known as type I, II, III and IV starch, respectively (Mudgil and Barak, 2013). The resistant starch content of a food may change according to storage, temperature, water content, preparation and processing (Sajilata et al., 2006).

\section{Galacto-oligosaccharides (GOS)}

GOS molecules (Gal $(\beta 1 \rightarrow 4)$ Gal $(\beta 1 \rightarrow 4)$ Glc) (Gosling et al., 2010) are a group of oligomerics (Song et al., 2013), produced from lactose by glycosyl transfer of one or more D-galactosyl units onto D-galactose moiety of lactose catalysed by $\beta$-galactosidase (Martinez-Villaluenga et al., 2008).

\section{Soybean oligosaccharides (raffinose and stachyose)}

Soybean oligosaccharides are namely raffinose and stachyose: raffinose is a trisaccharide containing 
galactose linked $\alpha-(1-6)$ to the glucose unit of sucrose; stachyose is a tetrasaccharide containing a galactose linked $\alpha-(1-6)$ to the terminal galactose unit of raffinose (Kim et al., 2003).

\section{Polydextrose}

Polydextrose, a commercial available preparation, is a randomly linked polymer of glucose (Aidoo et al., 2014).

\section{Lignin}

Lignin is not a polysaccharide but is chemically bound to hemicellulose in the plant cell wall. The complete structure of lignin is not well defined (Chawla and Patil, 2010). Lignin acts as a matrix together with hemicelluloses for the cellulose microfibrials, which are formed by ordered polymer chains that contain tightly packed, crystalline regions (Fig. 1; Ghaffar et al., 2013).

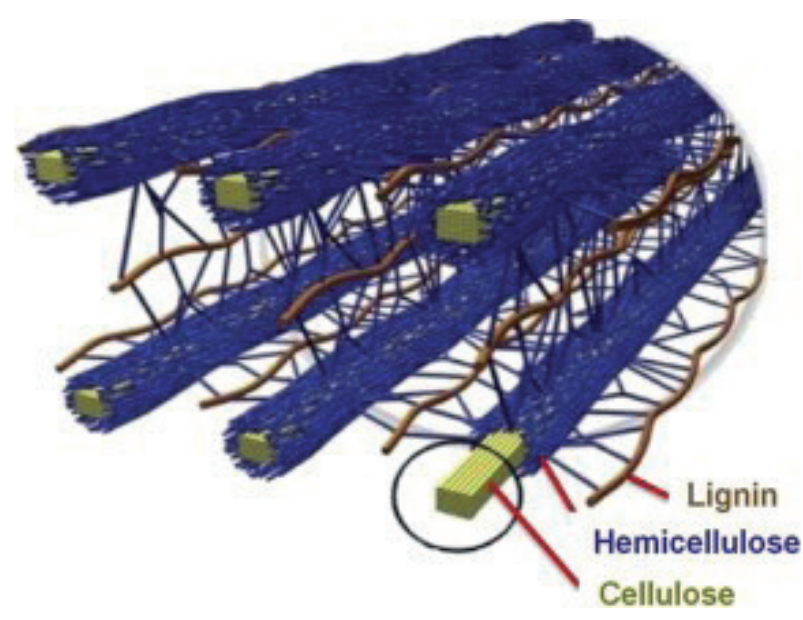

Fig. 1. Cellulose strands surrounded by hemicellulose and lignin (Doherty et al., 2011)

\section{Hydrocolloids (gum, mucilage)}

Food hydrocolloids consists of a vast and diverse number of ingredients sourced from algae, bacterial, fruit and plant extracts (Viebke et al., 2014). Gums or hydrocolloids are a rich source of soluble dietary fiber (Mudgil et al., 2011). Gum is not digested in the upper intestinal tract but is fermented in the large gut because of its resistance to human digestive enzymes. Its fermentation leads to the stimulation of the endogenous microflora and the production of short-chain fatty acids. Its health benefits are particularly well documented in the scientific literature (Kravtchenko, 1998). Mucilage is a high molecular weight polyuronide, including sugar and uronic acid units. It is partially soluble in water and can form a highly viscous solution. It exhibits a hampering effect on the diffusion of glucose, and helps to postpone the absorption and digestion of carbohydrates, which results in lowered postprandial blood glucose (Sangeethapriya and Siddhuraju, 2014).

\section{TECHNOLOGICAL PROPERTIES OF DIETARY FIBRE}

The functional properties of dietary fiber are related to the chemical composition and process conditions used to obtain food. The functional properties of a food material could enhance its utilization in food products. For example, water and oil interaction with food ingredients plays an important role in food texture and flavor, while the ability of flour to retain water and oil improves the mouthfeel of a food product and helps to reduce fat and moisture losses. Syneresis in food products is controlled by adding food ingredients with a high water-holding capacity (WHC). In formulated food with a high fat content, food ingredients with high oil-holding capacity $(\mathrm{OHC})$ are added to act as emulsifiers. Good control over the water activity of food is necessary to maintain its texture, microbial safety, and to hold back detrimental chemical and enzymatic changes.

The technological effects known as functional properties of dietary fibres depend mainly on their physicochemical properties: size of the particle, solubility, water-holding capacity, viscosity and gel formation, binding ability, bulking ability, swelling, cation exchange, fermentability (Mudgil and Barak, 2013) and antioxidant properties (Elleuch et al., 2011), among others.

\section{Solubility}

Solubility has profound effects on fibre functionality and chemical composition affects it. Branching, the presence of ionic groups and the potential for inter unit positional bonding increases the solubility. Moreover, changes in monosaccharide units and their molecular form ( $\alpha$ - or $\beta$-form) also increase solubility. 
Virtually, there are two types of dietary fibre, defined by their physical behaviour in water: insoluble fibre, which are abundant in whole grain cereals, and soluble fibre, present especially in fresh vegetables, legumes and fruit, oats, barley and some yeasts (Salas-Salvado et al., 2006). Most vegetable products contain a mixture of soluble and insoluble fibre in a proportion of approximately 1:3. Although all food contains both soluble and insoluble fibre, oats (and particularly oat bran), barley, legumes, apples and citrus fruits contain the highest quantities of soluble fibre, while wheat bran, bread and wholegrain cereals contain greater quantities of insoluble fibre. Different plant foods contain different amounts and types of fibre. Whole wheat flour, bran and vegetables are, in general, good sources of cellulose, while bran and whole grain cereals contain sizeable amounts of hemicellulose. Lignin is mainly found in ripe vegetables, wheat and some edible seeded fruits, such as strawberries. The total lignin content of the diet is very low, approximately $1 \mathrm{~g} / \mathrm{d}$, and mainly comes from wheat and fruit, vegetables with skin, and/or edible seeds. Oats, barley and legumes (from which 'guar' is derived) are rich in gum, while apples, citrus fruits, strawberries and carrots contain appreciable amounts of pectin. There is little difference in the content of fibre of raw and cooked fruits or vegetables, although its quality and structure may vary. Nuts are particularly rich in cellulose, followed by hemicellulose, pectin and lignin (Marlett, 1992; Salas-Salvado et al., 2006).

\section{Water-holding capacity (WHC)}

Dietary fiber is colloid-like, bulky and difficult to process because of its water-holding capacity (Ramaswamy et al., 2013). Water-holding capacity (WHC) was given in the literature as different definitions. According to Robertson et al. (2000), the amount of water bound or retained by a known weight of fibre under defined conditions might be termed water-holding capacity. WHC is mainly measured in 2 ways: (a) dispersing the sample in excess water in certain conditions (timetemperature), followed by the removal of the unabsorbed water using pressure, filtration or centrifugation and then measurement of the water bound by gravimetry or (b) measuring the water uptake in conditions of limited water. The water-holding capacity (WHC) can thus be estimated as the amount of water released from the sample (water retention measurement) or as the amount of water absorbed or bound by the sample (water absorption measurement). In the first case, only insoluble fibres (or with a high quantity of insoluble fibres) can be analysed, while the second method allows the impact of soluble fibres to be taken into account. These methods allow fibres to be classified with regard to their affinity for water (Villemejane et al., 2013).

\section{Viscosity and gel formation}

The viscosity of a liquid refers to its resistance to flow, informally described as "thickness", whereas gelation is the cross-linking and formation of three-dimensional networks of molecules that can entrap the liquid and behave like solids, which is commonly called "gel" (Wanders et al., 2014). Moreover, while the molecular weight and chain length of fibre increases, the viscosity of fibre in a solution increases. Nevertheless, the concentration of the fibre in the solution, the temperature, $\mathrm{pH}$, shear conditions of processing and ionic strength changes according to the fibre used. Soluble fibres, such as guar gum and psyllium, promote relatively high viscosities in comparison to insoluble fibres such as cellulose, rice bran, and wheat bran. Soluble fibers form gels, increasing the viscosity of the contents of the gastrointestinal tract (Fabek et al., 2014). For example; long chain polymers (guar gum, tragacanth gum) bind significant water and exhibit high solution viscosity, but highly soluble fibres (gum arabic) have low viscosities.

\section{Oil holding capacity (OHC)}

Oil holding capacity $(\mathrm{OHC})$ is the amount of oil retained by the fibres after mixing, incubation with oil and centrifugation. Oil absorption of cereal derivatives, e.g., wheat bran, is related mainly to the surface properties of the bran particles, but may also be related to the overall charge density and to the hydrophilic nature of the constituents, e.g., alginate and fucan, of the algae (Elleuch et al., 2011).

\section{Fermentability}

Fermentation of soluble fibers may play an important role in some physiologic effects of fiber. Plants contain varying proportions of rapidly fermented, slowly fermented, and unfermentable dietary fibers (Guillon et al., 1998; Norlund et al., 2013; Silvio et al., 2000). 


\section{Binding affinity}

Impaired mineral absorption is supplied by fibre because of binding metal ions to charged polysaccharide. Charged polysaccharides do not have an effect on mineral and trace element absorption. The environmental conditions (duration of exposure, $\mathrm{pH}$ ) and the physical and chemical forms of fibres can influence its adsorption capacity.

\section{FOOD PROCESSING}

The structure, physicochemical properties and nutrition effects of dietary fibre are easily affected by food processing (Zhang et al., 2011). Moreover, various processing steps also lead to the modification of fibre compositions and microstructure, which in turn lead to both desirable and undesirable changes in the functional and nutritional properties of the fibre.
The processing conditions (e.g. temperature, pressure vb. of soaking and extrusion cooking, and micron technology) can also change the dietary fibre composition considerably, thereby affecting the physicochemical and nutritive value of dietary fibre using chemical, mechanical, enzymatic and thermal processes. The functionality of DF is attributed to its physicochemical properties such as water solubility, water-holding capacity, swelling power, and rheological properties. DF has received special attention, since the physicochemical and metabolic properties influence.

\section{Chemical processes}

Chemical treatments with acidic or basic solutions of fibers can increase the swelling capacity of IDF, which could be explained by the damage to the coherence of the cell walls. To enhance the dietary fiber functions, different chemical modifications (e.g. acid hydrolysis,

Table 1. The effect of technological treatment on functional properties of dietary fiber

\begin{tabular}{|c|c|c|c|}
\hline Sources & Technological treatment & Results & References \\
\hline $\begin{array}{l}\text { Sugarcane bagasse } \\
\text { Whey protein } \\
\text { concentrate } \\
\text { Corn starch }\end{array}$ & $\begin{array}{l}\text { Extrusion (constant at } \\
\left.60^{\circ} \mathrm{C} \text { and } 90^{\circ} \mathrm{C} ; 38 \mathrm{rpm}\right)\end{array}$ & $\begin{array}{l}\text { High extrusion conditions increased the values of } \\
\text { the water absorption index, solubility index, and } \\
\text { penetration and decreased the adhesive force in gels. }\end{array}$ & $\begin{array}{l}\text { Martinez-Bustos et al., } \\
2011\end{array}$ \\
\hline Orange pomace & $\begin{array}{l}\text { Extrusion }(115,125 \\
135^{\circ} \mathrm{C} ; 230,290 \\
\text { and } 350 \mathrm{rpm})\end{array}$ & $\begin{array}{l}\text { The physicochemical properties (water-holding } \\
\text { capacity, oil-holding capacity, swelling property, } \\
\text { and cation-exchange capacity) improved compared } \\
\text { to the unextruded sample. }\end{array}$ & Huang and Ma, 2016 \\
\hline Okara & $\begin{array}{l}\text { HHP-treatment }(200 \text { and } \\
400 \mathrm{MPa}) \text { at } 30 \text { and } 60^{\circ} \mathrm{C}\end{array}$ & $\begin{array}{l}\text { The physicochemical properties increased with } \\
\text { increasing hydrostatic pressure and temperature. } \\
\text { The effect of combined hydration, mild temperature } \\
\text { and HHP-treatment should be considered in order to } \\
\text { improve the functionality of okara. }\end{array}$ & $\begin{array}{l}\text { Mateos Aparicio et al., } \\
2011\end{array}$ \\
\hline Wheat bran & $\begin{array}{l}\text { High pressure homog- } \\
\text { enizer treatment }\end{array}$ & $\begin{array}{l}\text { As the particle size decreased, the water-holding } \\
\text { capacity, swelling capacity, oil-holding capacity, } \\
\text { and cation-exchange capacity were increased. }\end{array}$ & An et al., 2014 \\
\hline Coconut residue & Grinding $(1.127-550 \mu \mathrm{m})$ & $\begin{array}{l}\text { The oil-holding capacity was increased, while parti- } \\
\text { cle size decreased. }\end{array}$ & Raghavendra et al., 2006 \\
\hline Pumpkin & Peeling & $\begin{array}{l}\text { Unpeeled pumpkin had a higher water-holding } \\
\text { capacity and oil-holding capacity than peeled } \\
\text { pumpkin. }\end{array}$ & $\begin{array}{l}\text { Aziah and Komathi, } \\
2009\end{array}$ \\
\hline
\end{tabular}


oxidation, etherification, esterification and cross-linking) have been carried out. Park et al. (2013) carried out a study to obtain cross-linked (CL), dietary fiber (DF), carboxymethyl (CM) DF, and hydroxypropyl (HP) DF with chemical modification from whole grain barley. Their findings showed an increase in the total DF (TDF) content of CL- and HP-DF. Carboxymethyl led to an appreciable decrease in TDF. Chemical modification might be recommended to exploit its potential application as a functional ingredient in fiber-rich products. Huang et al. (2015) used chemical treatment [water bath of 1-3 h, water bath temperature of 50$90^{\circ} \mathrm{C}, \mathrm{Na}_{2} \mathrm{HPO}_{4}$ concentration of $0.1-0.9 \%$ and sample/reagent radio $(\mathrm{S} / \mathrm{R})$ of 1:40-1:60 (w/v)] to evaluate the changes in physicochemical and physiological properties of modified soluble dietary fibre (mSDF) in the okara and found that the mSDF yield increased with chemical treatment and the swelling capacity of mSDF improved.

\section{Mechanical processes}

Mechanical processes are often included in this type of work in order to study the impact of processing on the physicochemical properties of fibers, allowing changes occurring on an industrial scale to be understood. Some of these changes are related to particle properties, concentration and chemical composition. Particle sizes of fibre depend on their degree of processing and the type of cell walls present in the foods. Raghavendra et al. (2006) found that when the particle size of coconut residue reached 1.127-550 $\mu \mathrm{m}$, its hydration properties increased. Surface area and total pore volume as well as structural modification increased. As particle size increased $(>550 \mu \mathrm{m})$, the hydration properties decreased and the oil-holding capacity increased with a decrease in particle size. Zhu et al. (2014) studied the effect of buckwheat hull dietary fiber (DF) particle size (from $1.00 \mu \mathrm{m}$ to $133.10 \mu \mathrm{m}$ with a mean particle size of $12.50 \mu \mathrm{m}$ ) on its functional properties, with the buckwheat hull DF being ground by ultrafine grinding. As particle size decreased, soluble DF content increased, withthe water-holding capacity (WHC), water retention capacity (WRC), swelling capacity and oil binding capacity (OBC) increasing significantly. Zhu et al. (2010) also researched the effect of ultrafine grinding on the physicochemical properties of wheat bran dietary fiber (DF). Their findings showed that as particle size decreased, the hydration properties (water holding capacity, water retention capacity and swelling capacity) of wheat bran DF significantly decreased and a redistribution of fiber components from insoluble to soluble fractions was observed. Zhang et al. (2012) divided mushroom into small pieces prior to drying, using micronization methods, mechanical and jet millings and contrasted to shear pulverization. Six powders were prepared: shear pulverized cap (SPC) and stipe (SPS) powders; mechanically milled cap (MMC) and stipe (MMS) powders and jet milled cap (JMC) and stipe (JMS) powders. Compared to shear pulverization, mechanical and jet millings effectively reduced particle size. Powders from mechanical and jet millings had higher values in soluble dietary fiber content but lower water-holding values and swelling capacities than shear pulverized powder. Micronization methods greatly increased the soluble dietary fiber (SDF) fraction in the powders and jet milling behaved in a more effective way than mechanical milling.

Moreover, extrusion opens the fiber structure by mechanical shearing and releases free hydroxyl groups from cellulose available to bind with water. Jing and Chi (2013) applied extrusion technology for soluble dietary fibre extraction from soybean residue. In this study, the soluble dietary fibre content of soybean residue could reach $12.65 \%$ and that of the unextruded soybean residue reached $10.60 \%$. Furthermore, the dietary fibre in extruded soybean residue had a higher water retention capacity, oil retention capacity and swelling capacity than those of dietary fibre in unextruded soybean residue. Chen et al. (2014) investigated the effect of blasting extrusion processing (BEP) on the increase in soybean residue SDF content under optimal conditions $\left(170^{\circ} \mathrm{C}\right.$ and an extrusion screw speed of $150 \mathrm{r} / \mathrm{min}$ ). Compared with the control, the content of soluble dietary fiber from soybean residues treated by BEP (BEPSDF) increased from $2.6 \pm 0.3 \%$ to 30.1 $\pm 0.6 \%$. Moreover, BEPSDF showed improved water solubility, water retention capacity and swelling capacity. Stojceska et al. (2010) showed how to increase the level of total dietary fibre in gluten-free products by using extrusion technology and by incorporating a number of different fruits and vegetables, such as apple, beetroot, carrot, cranberry and gluten-free teff 
flour cereal. Extrusion technology increased the levels of total dietary fibre in gluten-free products made from vegetables, fruits and gluten-free cereals according to the results of this study.

\section{Enzymatic processes}

Enzymatic treatment can also change the ratio between soluble and insoluble fibers. Zhou et al. (2012) reported that the water-holding capacity and swelling capacity of Tartary buckwheat (Fagopyrum tataricum Gaertn.) bran dietary fiber were improved after enzymatic treatment, due to the increase in SDF/IDF and the decreased size of dietary fiber particles.

Yi et al. (2014) evaluated the physico-chemical characteristics of dietary fibres with enzyme treatment from citrus juice by-products. The enzyme-treated sample had a dietary fiber content of $64.12 \mathrm{~g} / 100 \mathrm{~g}$. When compared to previous reported data, these enzyme-treated samples display higher favourable functional characteristics, such as enhanced water retention, increased swelling and oil-holding capacity than the water-bath-treated sample.

Wang et al. (2015) investigated the effects of extrusion-assisted enzymatic hydrolysis extraction process on the extraction rate and physicochemical properties of dietary fiber of rice bran. The results indicated that an extrusion-assisted enzymatic hydrolysis extraction process improved physicochemical properties of rice bran dietary fibers.

\section{Thermal processes}

Thermal treatments can change their physicochemical properties of dietary fiber by altering the ratio between soluble and insoluble fiber (SDF/IDF), total dietary fiber content. Lan et al. (2012) reported that steam processing and drying in sunshine affected the physicochemical properties of dietary fiber isolated from Polygonatum odoratum. Findings showed that when the steam processing applied the fiber extracts from $P$. odoratum, it displayed a significantly higher oil-holding capacity than that of drying in sunshine. However, that of drying in sunshine exhibited a significantly higher water-holding capacity and swelling power in comparison to that of steam processing. Garau et al. (2007) observed the physico-chemical properties of dietary fibre (DF) of orange peel and pulp remaining after juice extraction. These changes were largely dependent on air-drying temperature (from $30^{\circ} \mathrm{C}$ to $90^{\circ} \mathrm{C}$ ). In drying around $50-60^{\circ} \mathrm{C}$, pulp samples exhibited higher values of swelling (SW) than those derived from orange peel. Significant decreases in water retention capacity (WRC) and solubility values were detected for both by-products as the air-drying temperature increased. Benítez et al. (2011) focused on the effect of sterilisation on fibre physicochemical properties of onion by-products to evaluate the use of sterilised onion. Triturated onion wastes were named "Paste". After pressing, there was a liquid phase called as "Juice" and a solid residue phase named as "Bagasse". Sterilisation (at $115^{\circ} \mathrm{C}$ for $17-31 \mathrm{~min}$, depending on by-product and cultivar: Juice for $17 \mathrm{~min}$; Paste and Bagasse for $26 \mathrm{~min}$ ) took place in a conventional autoclave. These frozen by-products were used as the control. Swelling capacity decreased after sterilisation as a result of IDF losses, since insoluble fibres can adsorb water in the manner of a sponge. However, the water-holding capacity was not affected by changes with sterilisation, since this thermal treatment did not produce drastic changes in the free hydroxyl groups that adsorb water through hydrogen bonds. Yan and Kerr (2013) dried apple pomace with continuous vacuum-belt drying (VBD) at three different temperatures (either $80^{\circ} \mathrm{C}, 95^{\circ} \mathrm{C}$ or $110^{\circ} \mathrm{C}$ ) due to containing significant amounts of dietary fiber. TDF ranged from 442 to $495 \mathrm{~g} \cdot \mathrm{kg}^{-1}$ in vacuum-dried pomace and was not significantly different from TDF of freeze-dried pomace $\left(480 \mathrm{~g} \cdot \mathrm{kg}^{-1}\right)$.

At higher temperatures, drying dietary fiber can degrade some SDF components and alter their hydration properties and fat adsorption capacity (Garau et al., 2007). In extrusion, the amount of soluble dietary fibre produced is highly dependent on the temperature and pressure of the processes. In sum, high temperatures break down glucosidic bonds in polysaccharide, which can lead to the release of oligosaccharides and thus increase the quantity of SDF (Wolf, 2010). The dietary fibre from peach bagasse Prunus persica L. was obtained by a process involving ethanol pretreatment and subsequent microwave drying (de Escala de Pla et al., 2012). The use of $4.6 \mathrm{~mL}$ of ethanol $(96 \mathrm{~mL} / 100 \mathrm{~mL})$ per gram of tissue in the extraction step performed at $20^{\circ} \mathrm{C}$ for $15 \mathrm{~min}$ and a temperature of $55.0^{\circ} \mathrm{C}$ for drying in a microwave equipment working at a maximum power of $450 \mathrm{~W}$. The results 
showed that after air drying was used, oil-holding capacity decreased. Moreover water retention capacity (WRC) was higher than that reported in the literature for dietary fiber obtained from peach bagasse submitted to water washing. Piwińska et al. (2016) added oat $\beta$-glucan fiber to pasta dough at levels of $40,80,120$, 160 , and $200 \mathrm{~g} / \mathrm{kg}$ and the pasta was dried at a very high temperature and in a vacuum dryer. The swelling index, water uptake, and cooking loss were significantly higher in samples with oat $\beta$-glucan fiber powder compared to the control. Rashid et al. (2015) examined the suitability of wheat bran for extrusion cooking and checked the effect of different extrusion parameters on the dietary fibre profile as well as on the water solubility index. The results showed that extrusion cooking had a positive effect on total and soluble dietary fibre. This positive effect was probably due to disruption to the covalent and noncovalent bonds in the carbohydrate and protein moieties leading to smaller and more soluble molecular fragments. Water solubility index was greatly enhanced by varying the extrusion temperature and screw speed. Padalino et al. (2015) evaluated the effect of semolina and wholemeal flour from six durum wheat cultivars on pasta cooking. The wholemeal spaghetti samples showed an improvement in the chemical composition (high protein and insoluble dietary fibre content), although there was a decline in cooking quality compared to semolina spaghetti. Karlovic et al. (2009) conducted various different coating mixtures for coating chicken meat. Fibrex $(0.5 \%, 1.5 \%$ and $2.5 \%)$ and pectin $(0.5 \%, 1.5 \%$ and $2.5 \%)$ were added to the mixtures as dietary fibers. Meat fried at $180^{\circ} \mathrm{C}$ for 5 minutes and the effects of adding dietary fibers were evaluated. The addition of pectin or Fibrex to mixtures showed a significant decrease in oil uptake (up to $30 \%$ ). Water loss from meat decreased, and consequently, elasticity was much greater for samples coated with pectin or Fibrex coatings than for samples without dietary fiber coatings.

\section{Other processes}

High hydrostatic pressure (HHP) treatment is considered one of the most economically viable of the nonthermal technologies that improve the appearance, flavor, texture and nutritional quality of foods (Hernandez-Carrion et al., 2014). Wennberg and
Nyman (2004) used to modify the physico-chemical properties of dietary fibre in white cabbage (Brassica oleracea var. capitata) with high hydrostatic pressure (HHP) subjected to high-pressure treatment ( 400 and $500 \mathrm{MPa})$ at different temperatures $(20,50$ and $80^{\circ} \mathrm{C}$ ). When the pressure applied was $400 \mathrm{MPa}$, the proportion of soluble fibre was reduced at all temperatures. However, no additional effects were seen when the pressure was increased to $500 \mathrm{MPa}$. This study therefore showed that the solubility of dietary fibre can be decreased in white cabbage with high-pressure treatment. $\mathrm{Ma}$ and $\mathrm{Mu}$ (2016) evaluated the effects of high hydrostatic pressure (HHP) as well as enzyme (laccase and cellulase) treatment on the structural, physicochemical and functional properties of deoiled cumin dietary fiber (DF). HHP-enzyme treatment increased the contents of soluble dietary fiber (SDF) and water retention capacity, water swelling capacity and oil-holding capacity of DF modified by HHP-enzyme treatment improved.

Rabetafika et al. (2014) carried out in order to decrease the free monosaccharide content in fruit pomaces and to concentrate the dietary fibre using the desugaring step for dietetic and light-coloured foods, so water washing in mild conditions was applied to dry fruit pomaces in order to avoid loss of soluble fibres. The results show that desugaring increased the dietary finer content in fruit pomace in addition to fibre concentrates having improved water-holding capacity and swelling capacity but no significant effect on oil-holding capacity.

\section{CONCLUSION}

Recently, dietary fiber, which is mostly derived from cereals, vegetables and fruits, has gained attention due to its functional properties. These functional properties depend on the food sources, extraction methods, chemical composition, structure, and particle size of dietary fiber. Recent research concerning these properties can change the different processing applied. Processing conditions also change the composition and microstructure of DFs, which, in turn, lead to desirable and undesirable effects on their physicochemical and functional properties. However, further information is needed to study the effect of different processing methods. 


\section{REFERENCES}

Aidoo, R. P., Afoakwa, E. O., Dewettinck, K. (2014). Optimization of inulin and polydextrose mixtures as sucrose replacers during sugar-free chocolate manufacture Rheological, microstructure and physical quality characteristics. J. Food Eng., 126, 35-42.

Almeida, E. L., Chang, Y. K., Steel, C. J. (2013). Dietary fibre sources in bread. Inf. Techn. Qual., 50, 545-553.

An, E. M., Lee, J. K., Choi, Y. S., Kim, Y. H., Shin, H. S. (2014). Physicochemical properties of wheat bran in different areas prepared by a high-pressure homogenizer process. Korean J. Food Sci. Techn., 46, 4, 404-409.

Benítez, V., Mollá, E., Martín-Cabrejas, M. A., Aguilera, Y., López-Andréu, F. J., Esteban, R. M. (2011). Effect of sterilisation on dietary fibre and physicochemical properties of onion by-products. Food Chem., 127, 501-507.

Buttriss, L., Stokes, C. S. (2008). Dietary fibre and health: an overview. Nutr. Bull., 33, 186-200.

Celebioglu, H. Y., Cekmecelioglu, D., Dervisoglu, M., Kahyaoglu, T. (2012). Effect of extraction conditions on hemicellulose yields and optimisation for industrial processes. Int. J. Food Sci. Techn., 47, 2597-2605.

Chawla, R., Patil, G. R. (2010). Soluble dietary fiber. Compr. Rev. Food Sci. Food Safety, 9, 2, 178-196.

Chen, Y., Ye, R., Yin, L., Zhang, N. (2014). Novel blasting extrusion processing improved the physicochemical properties of soluble dietary fiber from soybean residue and in vivo evaluation. J. Food Eng., 120, 1-8.

Colin-Henrion, M., Mehinagic, E., Renard, C. M. G. C., Richomme, P., Jourjon, F. (2009). From apple to applesauce: Processing effects on dietary fibres and cell wall polysaccharides. Food Chem., 117, 254-260.

Cummings, J. H., Edmond, L. M., Magee, E. A. (2004). Dietary carbohydrates and health: do we still need the fibre concept? Clin. Nutr. (suppl.), 1, 5-17.

de Escalada Pla, M. F., González, P., Sette, P., Portillo, F., Rojas, A. M., Gerschenson, L. N. (2012). Effect of processing on physico-chemical characteristics of dietary fibre concentrates obtained from peach (Prunus persica L.) peel and pulp. Food Res. Int., 49, 184-192.

Dodevska, M. S., Djordjevic, B. I., Sobajic, S. S., Miletic, I. D., Djordjevic, P. B., Dimitrijevic-Sreckovic, V. S. (2013). Characterisation of dietary fibre components in cereals and legumes used in Serbian diet. Food Chem., 141, 1624-1629.

Doherty, W. O. S., Mousavioun, P., Fellows, C. M. (2011). Value-adding to cellulosic ethanol: lignin polymers. Ind. Crop. Prod., 33, 259-276.
Dziedzic, K., Górecka, D., Kucharska, M, Przybylska, B. (2012). Influence of technological process during buckwheat groats production on dietary fibre content and sorption of bile acids. Food Res. Int., 47, 279-283.

Fabek, H., Messerschmidt, S., Brulport, V., Goff, H. D. (2014). The effect of in vitro digestive processes on the viscosity of dietary fibres and their influence on glucose diffusion. Food Hydrocoll., 35, 718-726.

Ferguson, L. R., Chavan, R. R., Harris, P. J. (2001). Changing concepts of dietary fiber: Implications for carcinogenesis. Nutr. Cancer, 30, 155-169.

Foschia, M., Peressini, D., Sensidoni, A., Brennan, C. S. (2013). The effects of dietary fibre addition on the quality of common cereal products. J. Cereal Sci., 58, 216-227.

Franck, A., Levecke, B. (2012). Inulin. Weinheim: Wiley. Garau, M. C., Simal, S., Rossello, C., Femenia, A. (2007). Effect of air-drying temperature on physico-chemical properties of dietary fibre and antioxidant capacity of orange (Citrus aurantium v. Canoneta) by-products. Food Chem., 104, 1014-1024.

Ghaffar, S. H., Fan, M. (2013). Structural analysis for lignin characteristics in biomass straw. Biomass Bioener., 57, 264-279.

Gosling, A., Stevens, G. W., Barber, A. R., Kentish, S. E., Gras, S. L. (2010). Recent advances refining galactooligosaccharide production from lactose. Food Chem., 121, 307-318.

Guillon, F., Auffret, A., Robertson, J. A., Thibault, J. F., Barry, J. L. (1998). Relationships between physical characteristics of sugar-beet fibre and its fermentability by human faecal flora. Carbohydr. Polym., 37, 185-197.

Hernandez-Carrion, M., Vazquez-Gutierrez, J. L., Hernando, I., Quiles, A. (2014). Impact of high hydrostatic pressure and pasteurization on the structure and the extractability of bioactive compounds of persimmon "Rojo Brillante". J. Food Sci., 79, 32-38.

Hollmann, J., Themeier, H., Neese, U., Lindhauer, M. G. (2013). Dietary fibre fractions in cereal foods measured by a new integrated AOAC method. Food Chem., 140, 586-589.

Huang, S., He, Y., Zou, Y., Liu, Z. (2015). Modification of insoluble dietary fibres in soya bean okara and their physicochemical properties. Int. J. Food Sci. Techn., 50, 2606-2613.

Huang, S., He, Y., Zou, Y., Liu, Z. (2015). Modification of insoluble dietary fibres in soya bean okara and their physicochemical properties. Int. J. Food Sci. Techn., 50, 2606-2613. 
Huang, Y. L., Ma, Y. S. (2016). The effect of extrusion processing on the physiochemical properties of extruded orange pomace. Food Chem., 192, 363-369.

Jing, Y., Chi, Y. J. (2013). Effects of twin-screw extrusion on soluble dietary fibre and physicochemical properties of soybean residue. Food Chem., 138, 884-889.

Johansson, L., Virkki, L., Maunu, S., Lehto, M., Ekholm, P., Varo, P. (2000). Structural characterisation of water soluble b-glucan of oat bran. Carbohydr. Res., 42, 143-148.

Juturu, V., Wu, J. C. (2013). Insight into microbial hemicellulases other than xylanases: a review. J. Chem. Techn. Biotechn., 88, 353-363.

Karlovic, S., Jezek, D., Tripalo, B., Brncic, M., Bosiljkov, T. (2009). Effect of addiction of dietary fiber in coating mixture on a textural properties and oil uptake in deep fried chicken meat. Chem. Eng. Trans., 17, 945-950.

Kim, S., Kim, W., Hwang, I. K. (2003). Optimization of the extraction and purification of oligosaccharides from defatted soybean meal. Int. J. Food Sci. Techn., 38, 337-342.

Kravtchenko, T. P. (1998). The use of acacia gum as a source of soluble dietary fibre. In P. A. Williams, G. O. Phillips, Gums and Stabilisers for the Food Industry 9 (pp. 413-420). Cambridge: The Royal Society of Chemistry.

Lan, G., Chen, H., Chen, S., Tian, J. (2012). Chemical composition and physicochemical properties of dietary fiber from Polygonatum odoratum as affected by different processing methods. Food Res. Int., 49, 406-410.

Lattimer, J. M., Haub, M. D. (2010). Effects of dietary fiber and its components on metabolic health. Nutrients, 2 , $1266-1289$.

Leroy, G., Grongnet, J. F., Mabeau, S., Correa, D. L., BatyJulien, C. (2010). Changes in inulin and soluble sugar concentration in artichokes (Cynara scolymus L.) during storage. J. Sci. Food Agric., 90, 1203-1209.

Lu, Y., Mosier, N. S. (2008). Kinetic modeling analysis of maleic acid catalyzed hemicellulose hydrolysis in corn stover. Biotechn. Bioeng., 101, 6-15.

Ma, M., Mu, T. (2016). Modification of deoiled cumin dietary fiber with laccase and cellulase under high hydrostatic pressure. Carbohydr. Polym., 136, 87-94

Marlett, J. A. (1992). Content and composition of dietary fiber in 117 frequently consumed foods. J. Am. Diet. Assoc., 92, 175-186.

Martinez-Bustos, F., Viveros-Contreras, R., Galicia-Garcia, T., Nabeshima, E. H., Verdalet-Guzman I. (2011). Some functional characteristics of extruded blends of ber from sugarcane bagasse, whey protein concentrate, and corn starch. Ciênc. Tecnol. Aliment. Campinas, 31, 4, 870-878.
Martinez-Villaluenga, C., Cardelle-Cobas, A., Corzo, N., Olano, A. (2008). Study of galactooligosaccharide composition in commercial fermented milks. J. Food Comp. Anal., 21, 540-544.

Mateos-Aparicio, I., Mateos-Peinado, C., Rupérez, P. (2010). High hydrostatic pressure improves the functionality of dietary fibre in okara by-product from soybean. Innov. Food Sci. Emerg. Techn., 11, 445-450.

Mildner-Szkudlarz, S., Bajerska, J., Zawirska-Wojtasiak, R., Górecka, D. (2013). White grape pomace as a source of dietary fibre and polyphenols and its effect on physical and nutraceutical characteristics of wheat biscuits. J. Sci. Food Agric., 93, 389-395.

Molist, F., van Oostrum, M., Pérez, J. F., Mateos, G. G., Nyachoti, C. M., van der Aar, P. J. (2014). Relevance of functional properties of dietary fibre in diets for weanling pigs. Anim. Feed Sci. Technol., 189, 1-10.

Morris, C., Morris, G. A. (2012). The effect of inulin and fructo-oligosaccharide supplementation on the textural, rheological and sensory properties of bread and their role in weight management: A review. Food Chem., 133, 237-248.

Mudgil, D., Barak, S. (2013). Composition, properties and health benefits of indigestible carbohydrate polymers as dietary fiber: A review. Int. J. Biol. Macromol. 61, 1-6.

Mudgil, D., Barak, S., Khatkar, B. S. (2011). Effect of hydrocolloids on the quality characteristics of tomato ketchup. Carpathian J. Food Sci. Technol., 3, 39-43.

Noor Aziah, A. A., Komathi, C. A. (2009). Physicochemical and functional properties of peeled and unpeeled pumpkin flour. J. Food Sci., 74, 7, 328-333.

Nordlund, E., Katina, K., Aura, A. M., Poutanen, K. (2013). Changes in bran structure by bioprocessing with enzymes and yeast modifies the in vitro digestibility and fermentability of bran protein and dietary fibre complex. J. Cereal Sci., 58, 200-208.

Olson, A., Gray, G. M., Chiu, M. C. (1987). Chemistry and analysis of soluble dietary fibre. Food Technol., 41, 71-80.

Padalino, L., Mastromatteo, M., Lecce, L., Spinelli, S., Conte, A., Del Nobile, M. A. (2015). Effect of raw material on cooking quality and nutritional composition of durum wheat spaghetti. Int. J. Food Sci. Nutr., 66, 266-274.

Park, K. H., Lee, K. Y., Lee, H. G. (2013). Chemical composition and physicochemical properties of barley dietary fiber by chemical modification. Int. J. Biol. Macromol., 60, 360-365.

Philips, G. O. (2013). Dietary fibre: A chemical category or a health ingredient? Bioact. Carbohydr. Diet. Fibre, 1, 3-9. 
Piwińska, M., Wyrwisz, J., Kurek, M., Wierzbicka, A. (2016). Effect of oat $\beta$-glucan fiber powder and vacuumdrying on cooking quality and physical properties of pasta. CyTA - J. Food, 14, 101-108.

Prosky, L. (2000). When is dietary fiber considered a functional food? BioFactors, 12, 289-297.

Rabetafika, H. N., Bchir, B., Aguedo, M., Paquot, M., Blecker, C. (2014). Effects of processing on the compositions and physicochemical properties of fibre concentrate from cooked fruit pomaces. Food Bioproc. Technol., 7, 749-760.

Raghavendra, S. N., Ramachandra Swamy, S. R., Rastogi, N. K., Raghavarao, K. S. M. S., Kumar, S., Tharanathan, R. N. (2006). Grinding characteristics and hydration properties of coconut residue: A source of dietary fiber. J. Food Eng., 72, 281-286.

Ramaswamy, U. R., Kabel, M. A., Schols, H. A., Gruppen, H. (2013). Structural features and water holding capacities of pressed potato fibre polysaccharides. Carbohydr. Polym., 93, 589-596.

Rashid, S., Rakha, A., Anjum, F. M., Ahmed, W., Sohail, W. (2015). Effects of extrusion cooking on the dietary fibre content and Water Solubility Index of wheat bran extrudates. Int. J. Food Sci. Technol., 50, 1533-1537.

Redgwell, R. J., Fischer, M. (2005). Dietary fiber as a versatile food component: An industrial perspective. Mol. Nutr. Food Res., 49, 421-535.

Robertson, J. A., de Monredon, F. D., Dysseler, P., Guillon, F., Amado, R., Thibault, J. F. (2000). Hydration properties of dietary fibre and resistant starch: a European collaborative study. Lebensm.-Wiss. u.-Technol., 33, 72-79.

Sajilata, M. G., Singhal, R. S., Kulkarni, P. R. (2006). Resistant starch. A Review. Compr. Rev. Food Sci. Food Safety, 5 .

Salas-Salvado, J., Bullo, M., Perez-Heras, A., Ros, E. (2006). Dietary fibre, nuts and cardiovascular diseases. Brit. J. Nutr., 96, 45-51.

Sangeethapriya, M., Siddhuraj, P. (2014). Health related functional characteristics and antioxidant potential of mucilage (dietary fiber) from Zizyphus mauritiana fruit. Fruit Sci. Hum. Welln., 3, 79-88.

Schadel, C., Richter, A, Blochl, A., Hoch, G. (2010) Hemicellulose concentration and composition in plant cell walls under extreme carbon source-sink imbalances. Physiol. Plant., 139, 241-255.

Sila, D. N., Buggenhout, S. V., Duvetter, T., Fraeye, I., De Roeck, A., Loey, A. V., Hendrick, M. (2009). Processed fruits and vegetables: Part II. Structure. Function. Relationships. Compr. Rev. Food Sci. Food Safety, 8.
Silvio, J., Harmon, D. L., Gross, K. L., McLeod, K. R. (2000). Influence of fiber fermentability on nutrient digestion in the dog. Nutrition, 16, 289-295.

Slavin, J. L. (2005) Dietary fiber and body weight. Nutrition, 21, 411-418.

Song, L., Gao, Y., Zhang, X., Le, W. (2013). Galactooligosaccharide improves the animal survival and amyotrophic lateral sclerosis. Neuroscience, 246, 281-290.

Stojceska, V., Ainsworth, P., Plunkett, A., Ibanoglu, S. (2010). The advantage of using extrusion processing for increasing dietary fibre level in gluten-free products. Food Chem., 121, 156-164.

Tungland, B. C., Meyer, D. (2002). Nondigestible oligoand polysaccharides (dietary fiber): Their physiology and role in human health and food. Compr. Rev. Food Sci. Food Safety, 1, 90-109.

Viebke, C., Al-Assaf, S., Philips, G. O. (2014). Food hydrocolloids and health claims. Bioact. Carbohydr. Diet. Fibre, 4, 101-114.

Villegas, B., Carbonell, I., Costell, E. (2007). Inulin milk beverages: Sensory differences in thickness and creamines using r-1ndex analysis of the ranking data. J. Sens. Stud., 22, 377-393.

Villemejane, C., Roussel, P., Berland, S., Aymard, P., Michon, C. (2013). Technological and sensory tools to characterize the consistency and performance of fibreenriched biscuit doughs. J. Cereal Sci., 57, 551-559.

Wanders, A. J., Feskens, E. J. M., Jonathan, M. C., Schols, H. A., Graaf, C., Mars, M. (2014). Pectin is not pectin: A randomized trial on the effect of different physicochemical properties of dietary fiber on appetite and energy intake. Physiol. Behav., 128, 212-219.

Wang, X., Xu, Y., Liang, D., Yan, X., Shi, H., Sun, Y. (2015). Extrusion-assisted enzymatic hydrolysis extraction process of rice bran dietary fiber. In American Society of Agricultural and Biological Engineers Annual International Meeting 2015 (pp. 1337-1345). New Orleans, Louisiana, USA, 26-29 July 2015.

Wennberg, M., Nyman, M. (2004). On the possibility of using high pressure treatment to modify physico-chemical properties of dietary fibre in white cabbage (Brassica oleracea var. capitata). Inn. Food Sci. Emerg. Technol., $5,171-177$.

Westenbrink, S., Brunt, K., van der Kamp, J., W. (2013). Dietary fibre: Challenges in production and use of food composition data. Food Chem., 140, 562-567.

Wolf, B. (2010). Polysaccharide functionality through extrusion cooking. Curr. Opin. Coll. Interface Sci., 15, 1, $50-54$. 
Yan, H., Kerr, W. L. (2013). Total phenolics content, anthocyanins, and dietary fiber content of apple pomace powders produced by vacuum-belt drying. J. Sci. Food Agric., 93, 1499-1504.

Yi, T., Wang, K., Zhuang, Z., Pan, S., Huang, X. (2014). Comparative analysis of dietary fibre extract isolated from citrus juice by-products using water extraction, fermentation and enzymatic treatment methods. Adv. J. Food Sci. Technol., 6, 9, 1058-1066.

Yoo, S. H., Lee, B. H., Lee, H., Lee, S., Bae, I., Y., Lee, H., G., Fishman, M. L., Chau, H. K., Savary, B. J., Hotchkiss., A. T. (2012). Structural characteristics of pumpkin pectin extracted by microwave heating. J. Food Sci., 77, 11.

Zhang, M., Bai, X., Zhang, Z. (2011). Extrusion process improves the functionality of soluble dietary fiber in oat bran. J. Cereal Sci., 54, 98-103.
Zhang, Z., Song, H., Peng, Z., Luo, Q., Ming, J., Zhao, G. (2012). Characterization of stipe and cap powders of mushroom (Lentinus edodes) prepared by different grinding methods. J. Food Eng., 109, 406-413.

Zhou, X., Qian, Y., Zhou, Y., Zhang, R. (2012). Effect of enzymatic extraction treatment on physicochemical properties, microstructure and nutrient composition of tartary buckwheat bran: A new source of antioxidant dietary fiber. Adv. Mater. Res., 396-398, 2052-2059.

Zhu, F., Du, B., Li, R., Li, J. (2014). Effect of micronization technology on physicochemical and antioxidant properties of dietary fiber from buckwheat hulls. Biocatal. Agric. Biotechn., 3, 30-34.

Zhu, K. X., Huang, S., Peng, W., Qian, H. F., Zhou, H. M. (2010). Effect of ultrafine grinding on hydration and antioxidant properties of wheat bran dietary fiber. Food Res. Int., 43, 943-948. 
